spinal lesion. The conditions which ensue are very analogous to those which occur with increased respiratory resistance. There is an inability of the respiratory muscles to ventilate the alveoli adequately, and thus a pronounced degree of arterial anoxaemia and carbon dioxide retention occurs. The oxygen want can be to some extent overcome by the inhalation of oxygen, but the increased elimination of carbon dioxide cannot be accomplished. If relief of the spinal lesion can be expected within a reasonable time, properly controlled methods of artificial respiration may be instituted in order to reduce the uncompensated carbon dioxide acidosis which is apt to occur. This may be helped in some degree by the administration of alkalis in large quantities.

\section{Treatment of Dyspnoea.}

The treatment of dyspnoea in pulmonary diseases is very unsatisfactory unless the cause can be removed. In cases of respiratory obstruction, laryngeal diphtheria, or asthma, the first object to be attained is removal of the obstruction. If this be accomplished the relief is extremely prompt, as when the bronchial spasm is relieved in asthma by the administration of adrenaline.

We have at present few drugs which we know from actual observation relieve the dyspnoea which occurs in many pulmonary lesions. The evidence upon which respiratory stimulants are given is at present very scanty, and there is comparatively little proof to indicate that they are at all efficacious. On the other hand, the proper use of oxygen and carbon dioxide is of the greatest importance. In all acute cases which show any degree of cyanosis oxygen should be administered promptly and in sufficient quantity. This can only be done if proper methods are employed. The use of the so-called funnel method is to be condemned, as the quantity of oxygen allowed to pass through the funnel is usually ludicrously inadequate, and there is evidence to prove that it does not enrich the inspired air. On the other hand, the use of properly fitting masks and the regulation of the amount of oxygen given, or the use of a nasal catheter with a similar control, gives very good results (Table III). TABLE III.-Shouting the Effect of Oxygen Administration on the
Cerebral Symptoms in Cases of Lobar Pneumonia with Lowered Oxygen Saturation of the Arterial Blood.

\begin{tabular}{|c|c|c|c|c|c|c|c|}
\hline No. & 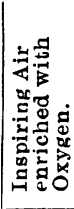 & 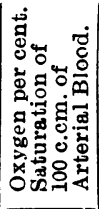 & $\begin{array}{c}\text { Cerebral } \\
\text { Symptoms. }\end{array}$ & No. & 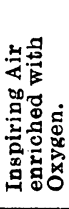 & 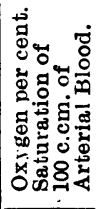 & $\begin{array}{c}\text { Cerebral } \\
\text { Symptoms. }\end{array}$ \\
\hline \multirow[t]{6}{*}{1} & - & 83 & Slight delirium. & 3 & - & 80 & Semi-comatoso. \\
\hline & - & 82 & Delirious. & & + & 94 & Quite rational. \\
\hline & + & 91 & No delirium. & 4 & - & 87 & Delirious. \\
\hline & + & 92 & No delirium. & & + & 90 & Slight delirium. \\
\hline & - & 84 & Very restless. & 5 & - & 81 & Semi-delirlous. \\
\hline & + & 97 & No delirium. & & + & 93 & No dellirium. \\
\hline \multirow[t]{2}{*}{2} & - & 89 & Restless. & 6 & - & 79 & Delirious. \\
\hline & + & 98 & $\begin{array}{l}\text { Very comfort- } \\
\text { able. }\end{array}$ & & + & 98 & No delirium. \\
\hline
\end{tabular}

The ideal, of course, would be to place the patient in an atmosphere rich in oxygen without the disturbance and discomfort of the mechanical appliances already mentioned.

Up to the present sufficient attention has not been given to the therapeutic use of carbon dioxide. In many cases it might be expected that a pronounced decrease in the carbon dioxide content of the arterial blood and of the tissues occurs, as in the case reported by Harrop. In such instances the administration of carbon dioxide after a proper manner would most probably have rery beneficial results. The work of Yandell Henderson and Haggart on the acapnoea which they have shown follows upon operative and other procedures needs thorough clinical investigation. REFERENCES

1 Dallinger: Journ. Roy. Micruscop. Society, 1887, vol. 7, p. 185. 2 Davies, Haldane, and Priestley t Journ. of Physiol., 1919, liil, 60 . Priestley : Journ. of physiol., 1919, lii, 420.5 Harrop : Journ. Amer. Med. A 880c., 1923, Ixxxi, 452. B Barach and Woodwell: Arch. Int. Med., 1921., xxviii, 421.' T Sharpey Schafer: Quart. Journ. Exper. Physiol., 1919, xili,

\section{A COMPARISON OF THE KAHN AND WASSER- MANN TESTS ON 500 SERUMS.}

BY

T. E. OSMOND, M.B.Cantab.,

PATHOLOGIST TO THE VENEREAL DEPARTMENT, ST. THOMAS'S HOSPITAL,

AND

DOUGLAS McCLEAN, M.B., B.S.LoNd., assistant pathologist.

THE Wassermann test for syphilis is so complicated that it can only be carried out by a highly trained and skilled pathologist working in a well fitted laboratory. Many workers have attempted, with varying success, to produce a simpler test which should be more delicate and reliable, and Kahn, in America, evolved a "precipito-agglutination" test $^{1}$ which, in its recent modification, ${ }^{2}$ seems to combine simplicity, brevity, and delicacy. Antigen and serum are mixed in varying given proportions and shaken, and the reading made; after a short period of incubation it is shaken again and a final reading taken.

It was considered that it would be of interest to compare this test with the Wassermann test in a series of serums from cases of treated and untreated syphilis and nonsyphilitic cases. Accordingly 500 serums were taken at random from the Venereal Diseases Clinic at St. Thomas's Hospital; in no instance was a patient seen by the authors, and no analysis of results was attempted until the series was complete.

The Wassermann test performed was No. 1 method Medical Research Council (Report Series No. 14), the routine test in this laboratory. The Kahn test was modified slightly from that described, ${ }^{2}$ and the technique was as follows :

1. Preparation of the Antigen." " Fresh beef heart is freed from fat, fibre, and blood vessels, and passed several times through a meat chopper. It is then spread in a thin layer on a porcelain platter and dried by means of a revolving fan. The dried material is broken into small particles and passed three times through a coffee grinder. Fifty grams of the dried heart muscle is then placed in a $500 \mathrm{c.cm}$. Erlenmeyer flask; sufficient ether is added to cover the dried material with an inch of fluid and it is placed in the icebox. After twenty-four hours' extraction the supernatant ether is box. After twenty-four hours' extraction the supernatant ether is
yellowish; it is then poured off and replaced with fresh ether. This is repeated daily for three days. On the fourth day the supernatant ether is water-clear. The ether is then filtered off and the ground muscle spread on paper and dried at room temperature until no odour of ether is detectable. This requires several hours' drying. To 20 grams of this material $100 \mathrm{c.cm}$. of absolute alcohol is added and the whole extracted for nine days in the ice-box and a day at room temperature. After this period the alcoholic extract is filtered room temperature. After this period the alcoholic extract is filtered Four milligrams of cholesterin are added to each cubic centimetre of alcoholic antigen.

2. Titration of the Antigen.-This was carried out as described by Kahn, though the reading did not appear so simple as suggested. It seemed, however, to be satisfactory to use equal parts of antigen and saline with each of the two antigens employed.

3. The Test Proper.-Tubes and racks, as for the Wassermann test, were employed. Pipettes were made by drawing out glass tubing and calibrating with mercury, marks being made witl grease pencil to indicate volumes of $0.15,0.05,0.025$, and 0.0125 c.cm. No doubt these could be obtained from an instrument maker, but they can easily be made by any pathologist. The same pipette is used throughout any given batch of tests. Three rows of tubes are set up, three tubes for each test. Into each tube of the first row is introduced $0.05 \mathrm{c.cm}$. of diluted antigen (obtained by pouring an equal quantity of 0.85 per cent. $\mathrm{NaCl}$ solution on to the neat antigen and inverting the tube several times), the point of the pipette being placed on the bottom of the tube. Similarly each tube of the second row receives $0.025 \mathrm{c.cm}$. of antigen, and of the third row $0.0125 \mathrm{~cm}$. The three tubes for each test then receive 0.15 of 0.15 c.cm. of the patient's serum previously heated to $56^{\circ} \mathrm{C}$. for half an hour. Controls are set up with antigen and saline insiead of serum. The racks containing the tubes are then shaken vigorously for three minutes (either by hand or by fixing the rack to a vaccine shaker) and a preliminary reading is then taken. This is carried out with the aid of an $X 6$ hand lens and a reading is carried as described by Dreyer and Ward for the Sigma test.4 (An ordinary electric light with a black shade answers the purpcse (A quite well.) Thich is the light front of the black background, behind whe being moved slightly to set up examined with the lens, the tube being moved slightly to set up a movement in any granules which may be present. After this preliminary reading all racks are placed in a water-bath at $37^{\circ} \mathrm{C}$. second time. 
Readings.-The controls should show a uniform opalescence, with no granules. In reading the test proper three forms of nomenno granules. In reading the test proper three forms of nomen-
clature are used for each tube: Positive (P) where the fluid shows clature are used for each tube : Positive ( $P$ where the fluid shows
clearing with definite granules (giving a hailstorm appearance); Doubtful (D) when there is some granulation but no clearing of the fluid; and Negative (N) where the fluid shows no trace of any granulation. A reading is taken of each of the three tubes of each test and recorded as PPP, DDD, or NNN, etc. Where one tube difiers from the other two the majority is accepted, thus: PDD is marked as doubtful, DNN as negative; whilst a reading such as PDN would be called " doubtful." The amount of precipitoagglutination does not depend on the amount of the antigen, since frequently the tube containing the smallest amount of antigen will show the most marked granulation.

In all cases the second reading is accepted as the decisive one. In fact, the preliminary reading may quite well be dispensed with, since it seems to serve no useful purpose.

The main modification introduced by the anthors into Kahn's technique were as follows :

1. The use of a hand lens instead of the naked eye, which makes the reading easier and probably gives a more delicate result.

2. The use of artificial light and a specially prepared dark background.

3. The interpretation of results. It appeared to the authors that it would be more satisfactory to decide whether each tube were positive, doubtful, or negative, and take the results of the three together, than to attempt to estimate the degree of precipitation in each tube and record it with a varying number of + signs. For example, PPP, PPD, PPN would indicate that the test was positive; DDD, DDP, DDN, PDN that it was doubtful; NNN, NNP, NND that it was negative.

In this series of tests two antigens were used; both gave the same tilrations, but with the second the readings were clearer and gave less "doubtful" reactions. This may be due to it having been more freshly prepared, the first one being three months old.

\section{Analysis of 500 Tests.}

Groups in which there was complete agrccment. 1. Kahn positive, W.R. positire ... 2. Kahn negative, W.R. negative
3. Kahn doubtful, W.R. doubtful

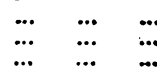
No. in Group.

$$
\text { Total ... }
$$

Groups in which there was some disagrecment

4. Kahn positive, W.R. negaliveIn favour of Kahn's test $\ldots \begin{array}{llll}\ldots & \ldots & \ldots & \ldots\end{array}$

5. Kahn positive, W.R. doubtfulSypiilitic, under treatment Probably syphilitio ... ...

6. Kahn doubtful, W.R. negativeSyphilitic, under treatment History of syphilis $\ldots$... Probably not syphilitio
Chancroid 12 days old 7. Kahn negative, W.R. doubtfulNo clinical evidence of syphilis

10. Kahn negative, W.R. positive Kahn test negative (non-syphilitio case)
Kaln test positive (case of treated syphilis)...

$$
\operatorname{Tctal} \ldots \quad \ldots \quad \ldots \quad \frac{2}{111}
$$

Note. - The 20 cases in Group 4 in favour of Kahn's test were either under treatment or gave a history of old syphilis; the patient with an apparently false positive Kahn defaulted, so that it was not possible to investigate his case further. Of the 9 cases in Group 6 which were probably not syphilitic 2, on repeating the Kahn test, showed a negatire result. The patient in Group 9 was syphilitic; she was two month pregnant, and had been treated with stabilarsan.

From the above analysis it will be seen that there was complete agreement in 389 cases (77.8 per cent. of the total), and some dis agreement in 111 (22.2 per cent.). Of the 111 showing disagreement, 24 tests (4.8 per cent. of total) were in favour of the Wassermann reaction, and 87 (17.4 per cent.) in favour of Kahn's test.

\section{Conclusions.}

It will be seen that the test is simple and easy and can be carried out after very little practice by anyone who has had a medical training. The apparatus and materials are inexpensive. The only difficulty is the preparation of the antigen. Only three reagents are required-physiological saline solution, antigen, and patient's serum. We have used racks holding four rows of twelve tubes each (one row being for the patient's serum), and find we can set up eleren tests with controls in ten minutes. Allowing five minutes for cach reading and five minutes for the two periods of shaking, eleven tests can be carried out in twenty minutes plus one hour for incubation. The test is therefore particularly applicable where small numbers of tests have to be done or a corroborative test is required, By using larger racks (to hold 96 or even more tubes) more tests can be carried out together, with a corresponding saving of time. The results (except for one possible "false positive" - see table, Group 4) compare very favourably with those of the Wassermann test. Of the 111 which disagreed, 87 (or 17.4 per cent. of total) were in favour of Kahn's test, whilst only 24 (or 4.8 per cent. of total) were in favour of the Wassermann test.

We would point out that whilst a "doubtful " Kahn's test is of little value in an untreated case of syphilis it would appear to be distinctly valuable in treated syphilis (see table, Group 6). It will be noticed (Group 10) that in two cases the Kahn test gave an unequivocal result where the serum was so anticomplementary that the Wassermann test failed.

A test which can be carried out by any medical practitioner in his surgery with so little apparatus deserves an extended trial. It does not seem to have attracted much attention in England, but in America it has been compared with the Wassermann test by a number of workers. For example, J. A. Kolmer ${ }^{5}$ found the Kahn test better on the whole in treated cases, and also in anticomplementary cases. Out of 1,000 cases there was agreement in 904 and disagreement in 96, the balance being in favour of Kahn's test. Litterer ${ }^{6}$ found the agreement with the Wassermann test surprisingly accurate. W. Levin, ${ }^{7}$ in a series of 258 serums, found complete agreement in 86.4 per cent., relative agreement in 12.8 per cent., and complete disagreement in 0.8 per cent. Sobei Ide and G. S. Smith ${ }^{8}$ think that the value of Kahn's test is almost as great as that of the Wassermann test. A series of 2,165 comparative tests gave the following results :

$$
\begin{array}{cccccccc} 
& & & \multicolumn{4}{c}{\text { Wassermann. }} & \text { Kahn. } \\
\text { Positive } & \ldots & \ldots & \ldots & \ldots & 396 & \ldots \ldots \ldots . & 423 \\
\text { Negative } & \ldots & \ldots & \ldots & \ldots & 1,769 & \ldots \ldots \ldots & 1,742
\end{array}
$$

C. C. Young' recommends that Kahn's test should be used in combination with the Wassermann.

Our thanks are due to Colonel L. W. Harrison, D.S.O., Director of the V.D. Department at St. Thomas's Hospital, for permission to publish the results of these tests.

Since writing the above some 500 more tests have been carried out. These confirm and emphasize the results given in the foregoing table.

${ }^{1}$ Kahn : Arch. Derm. and Syph. May, 1922, v, 570. 2 Kahn: Journ. Amer. Med. Assoc., 81, 2, p. 88. "Kahn and Wile Ibid., 79, 870, Sept., 1922. 'Dreyer and Ward: Lancet, 1921, i, 956. ' Kolmer: Journ. Aimer.

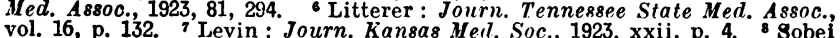

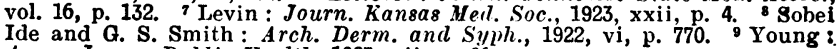
Amer. Journ. Public Health, 1923, xii, p. 96.

\section{A COLORIMETRIC METHOD FOR THE ESTIMATION OF DIASTASE IN BODY FLUIDS.}

\author{
I. COHEN, B.Sc.Lond., \\ ASSISTANT IN BIOCHEMISTRY; \\ AND
}

E. C. DODDS, M.B., B.S., B.Sc.Iond., CHEMICAL PATHOLOGIST TO AND LECTURER IN BIOCHEMISTRY,
MIDDLESEX HOSPITAL."

(From the Biochemical Department of the Bland-Sutton Institute of Pathology, the Middlesex Hospital.)

THE estimation of urinary diastase has been of clinical interest from the time it was first determined by Wohlgemuth in 1908. Since the publication of this observer's original results a great deal of work has been carried out on the technique of diastase estimation, and on the clinical value of the results so obtained. It is with the former that this paper is concerned.

In all the methods brought forward, the diastatic action is measured by the starch-splitting power of the solution containing the ferment. Either the amount of diastase solution required to digest completely a known amount of starch is measured by means of an achromic point method (Wohlgemuth $^{1}$ ), or else the products of starch digestion (maltose) are determined (Lovatt Evans, ${ }^{2}$ Fyfe $^{3}$ ). The former methods have found the greater popularity, undoubtedly owing to their simplicity. 